\title{
Research on New and Old Pavement Splicing Technology in Road Reconstruction and Expansion Projects
}

\author{
Mingli WU \\ School of Civil Engineering \\ University of South China \\ Hunan, China \\ e-mail:1732578519@qq.com
}

\author{
Xudong ZHU \\ School of Civil Engineering \\ University of South China \\ Hunan, China \\ e-mail:765494626@qq.com
}

\author{
Ming LI \\ School of Civil Engineering \\ University of South China \\ Hunan, China \\ e-mail: 1121446131@qq.com
}

\author{
Yong LI \\ School of Civil Engineering \\ University of South China \\ Hunan, China \\ e-mail: 1091797239@qq.com
}

\begin{abstract}
Based on the design proposal on the reconstruction of the Da Wei Jian Cai road section between the 107 National Highway and Songfeng Road in Hengyang, Analysis on mechanics response of the related pavement structure layer concerning the two different models established here through the Finite Element Analysis Software ABAQUS. The two different models are conceived according to whether the bottom of the new concrete base above the splicing seam-line on the new and old pavements buries steels. The results show that compared with the purely-simple concrete splicing, the new steel-burying concrete base above the splicing seam-line makes a striking decrease both in the maximum longitudinal tensile stress between layers and the vertical subsidence displacement at the bottom of the base. Besides, the adoption of steels in splicing seam-line can effectively separate the mechanics response and guarantee the load transfer between the longitudinal seam-lines, which to a certain extent, can effectively prevent the longitudinal seam from cracking.
\end{abstract}

Keywords-rebuilding and expansion projects; pavement splice; finite element analysis; mechanics response

\section{INTRODUCTION}

In recent years, with the increase of urban density and the increase of traffic demand, some of the old roads built before have been difficult to meet the needs of social development. In addition, due to the perennial operation of old roads, some road sections are damaged seriously, and service level reduced greatly, so it is necessary to carry out renovation and expansion of the old road. Most of the previous road reconstruction projects are based on the uncoordinated deformation of the old and new roadbeds and the related control measures, while the study of the old and new pavement structure is scarce. Ma Xiao-hui [1]-[2] by studying the different mechanical effects of pavement splice, consider that the old and new pavement decisive force is the old and new pavement layer and the base of the modulus difference. Xue Cheng [3] discussed the existing problems of old and new pavement structure in the extension project, and discussed the old pavement milling parts and technical control factors, that effectively prevent the crack expansion can be achieved by the top of the base layer polyester fiberglass cloth to achieve. Xiao Yi-min and Li Chang [4] think that the old and new pavement joints should be used in the way of joints, but also comparative analysis of the excavation steps and direct splicing under the carrying capacity. In general, for the road reconstruction and expansion project, most of the treatment schemes and technical indexes used in domestic research are qualitative and lack a comprehensive and systematic theoretical basis, which affects the technical level of the project to a great extent [5]. Therefore, it is urgent to find out the new and old pavement splice according to characteristics of the roads.

\section{II.PROJECT OVERVIEW}

107 National Highway to Da Wei Jian Cai road section, Hengyang City Songmu Industrial Park SongFeng Road expansion project. Songfeng Road is Hengyang City, one of the overall planning of the road, located in the pine industrial park. As the road on both sides of the vast majority of factories and mines have been formed, so virtually the road has become a park road network in a major traffic arteries, with the great increase in traffic, the existing $12 \mathrm{~m}$ of the roadway can not To meet the increasing traffic flow, the project is to maintain the original line plane to the same situation, according to the existing conditions of Songfeng Road, 12 meters wide roadway to the south of the pipe network and form the road form, To the north side of the road and section of the expansion of the roadway from the previous $12 \mathrm{~m}$ widened to $23 \mathrm{~m}$, and the road after years of operation and use, making the pavement road perennial tons of heavy truck operation, pavement concrete blocks and G107-Xinan road section of the main lane, destruction is quite serious, in addition to cracks and broken plate, local land also appeared in the settlement. Taking into account the Songfeng Road in Hengyang City is the first road into the Songmu industrial park, in order to improve driving comfort 
and park image, increase the use of Songfeng Road, the use of road efficiency, especially on the Songfeng Road, the entire section of the renovation and expansion.

\section{ROAD SURFACE SPLICING FORM}

At present, most of the old and new pavement splicing in two ways, the first is the pavement at all levels of splicing excavation steps, but in the construction of the following problems, due to the old water stable base age, the old pavement material strength loss much, and the excavation step is easy to appear loose state, causing excavation collapse or peeling, resulting in the old road grass edge edge irregular; The second is the homogeneous seam processing, the so-called seams, is the seams of the original There is a pavement structure along the horizontal edge of the vertical cut panels, and the new pavement structure of the direct splicing[4], but this treatment, to prevent the road surface cracking would not achieve the desired results.

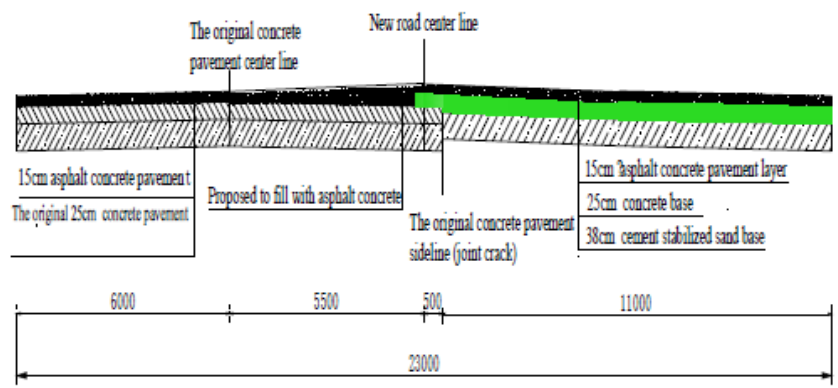

Figure 1. Road splicing form

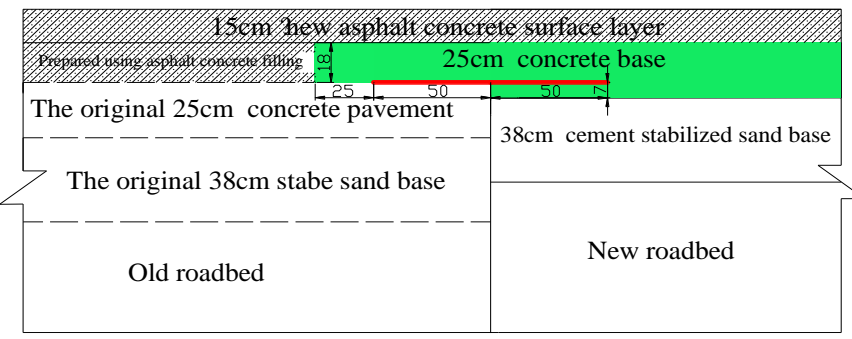

The original concrete pavement sideline(joint crack

Figure 2. Simplified road stitching detail

The renovation and expansion project of the stitching method, the old and new pavement surface layer of uniform use of asphalt concrete pavement, widening of the road using concrete base, the construction process, so that the new grass-roots paved directly in the old concrete pavement, the actual project new base layer take Shop length to take $750 \mathrm{~mm}$, as a result of the new grass-roots part of the ride in the old pavement, it makes the grassroots following the old and new pavement structure is not aligned stitching, but the upper and lower dislocation homogeneous seams. This method can directly embed the transverse reinforcement in the upper part of the joint, which avoids the complex construction process of anchoring anchorage and reduces the amount of the excavation step of the old road surface. The actual pavement cross-section structure layer as shown in
Figure 1, the spliced part is simplified as shown in Figure 2.

\section{SPlice PAVEMENT Finite ElEMENT ANALysis}

The original pavement is $12 \mathrm{~m}$ in width, $63 \mathrm{~cm}$ in thickness and $1.5 \%$ in slope. In order to enhance the integrity of the old and new pavement, unified asphalt concrete overlay, the construction process to make a part of the new concrete pavement directly in the old concrete pavement on the road, the pavement, And the upper part of the joint seam buried steel, the diameter of $16 \mathrm{~mm}$, length of $100 \mathrm{~cm}$, spacing of $40 \mathrm{~cm}$, with the new reinforced concrete base pouring. Table1 shows the material parameters of the relevant structural layers.

According to the stitching form of the road surface, the ABAQUS finite element software is used to build the three-dimensional solid model of the pavement structure. The length of the pavement is $5 \mathrm{~m}$ and the width is $4 \mathrm{~m}$, and the thickness of the pavement on both sides of the joint is inconsistent. , The old pavement thickness of $96 \mathrm{~cm}$, the new pavement thickness of $78 \mathrm{~cm}$, pavement structure using C3D20R unit type, and create 9125 nodes, 520 physical units, reinforced with Beam31 unit for discrete analysis.

1)Basic assumptions:

In order to facilitate the establishment of the model, three layers of asphalt concrete overlay into a layer to create a model, the thickness of $15 \mathrm{~cm}$. As the road grading rate is too small, in order to simplify the model, it is not considered. Because the deformation of new and old foundation is very small under the standard axial load and it is not the focus of this paper, the basement is not considered when building this model, but in order to simulate the actual working condition, the bottom is defined as elastic foundation. Material parameters in Table 1, the relevant road structure design specifications recommended values. The contact way of the old and new pavement is Coulomb friction, the coefficient is 0.6. The reinforcing bars in the upper part of the joint are embedded in the new concrete base and the old concrete pavement.

\section{2)Boundary conditions:}

Limit the lateral displacement of the lateral direction of the model, limit all the degrees of freedom of the bottom of the model, and rotate the other reinforcing bars in the $\mathrm{x}$-axis direction.

\section{3)Loading method:}

The top surface of the pavement acts as a standard road load, which is similar to a double circle uniform vertical load. Its equivalent circle radius $\mathrm{R}$ is $10.65 \mathrm{~cm}$, the center distance is $3 \mathrm{R}, 31.95 \mathrm{~cm}$ and the vertical contact pressure is $0.7 \mathrm{MPa}$. According to relevant data [6], according to the equivalence of load stress, the load form can be converted from double circle to double rectangle with $18.6 \mathrm{~cm} \times$ $19.2 \mathrm{~cm}$. This alternative method has little influence on the research results of pavement mechanical properties. The main purpose of this equivalent is to facilitate the subsequent grid division, in order to improve the efficiency of the model operation. 
TABLE I. CALCUlation PARAMETERS OF STRUCTURAL MATERIAL

\begin{tabular}{lccc}
\hline Material name & Thickness (CM) & Elastic Modulus (Mpa) & Poisson's ratio \\
\hline AC-13C Fine grained asphalt concrete & 4 & 1200 & 0.35 \\
AC-20C Medium-grained asphalt concrete & 5 & 1100 & 0.35 \\
AC-25C Coarse grained asphalt concrete & 6 & 1000 & 0.35 \\
New concrete base & 25 & 32500 & 0.15 \\
Old concrete pavement & 25 & 35500 & 0.15 \\
New 5\% Cement Stabilized Gravel Subbase & 20 & 550 & 0.25 \\
New 4\% cement stabilized gravel subbase & 18 & 500 & 0.25 \\
Old cement stabilized sand base & 38 & 600 & 0.25 \\
New roadbed & - & 40 & 0.4 \\
Old roadbed & - & 50 & 0.4
\end{tabular}

According to a number of domestic road lane survey shows that the vehicle on the road driving position is relatively fixed, rut is generally distributed in a specific width, research and investigation shows that [7] the vehicle wheel with most of the distribution in the middle lane on both sides $0.9 \mathrm{~m}$, where the probability of rutting the most. In this practical project, the widening pavement track of the road is located near the old and new pavement joints. Therefore, the model defines and applies the traffic load position at $0.4 \mathrm{~m}$ to the right of the new pavement on the right side of the seam, and longitudinally at the center of the pavement.

4)Meshing:

The meshes are modeled by hand control, the tetrahedral elements are used for the asphalt concrete overlay mesh, and the hexahedral elements are used for the other structural layers.

In summary, the created pavement structure model shown in Figure 3.

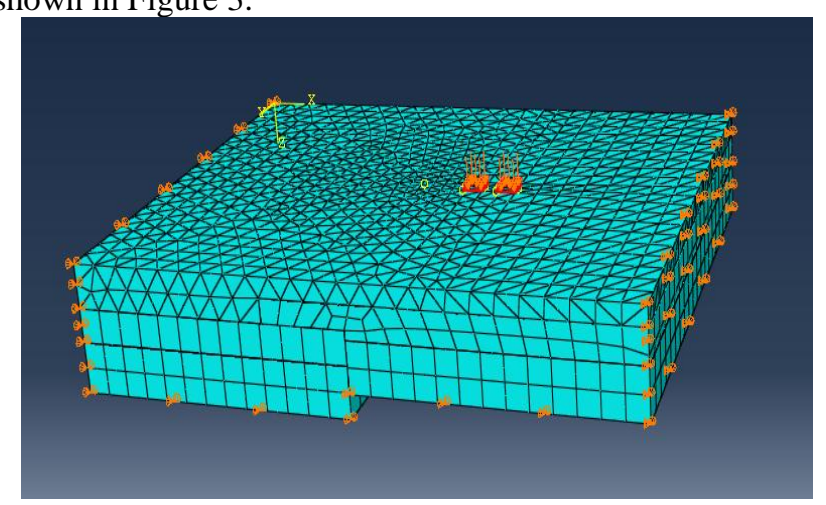

Figure 3. Finite element model under standard axle load

\section{V.COMPARISON OF TWO CONSTRUCTION PLANS TO ANALYZE THE STRESS AND DISPLACEMENT OF THE PAVEMENT MODEL}

In this paper, two kinds of model structures are established, which are corresponding to two construction schemes, namely construction scheme one: old and new pavement base with plain concrete splicing; construction scheme two: old and new pavement joint. The numerical analysis of the two models is carried out, and the direction of the cross section of the old and new pavement is taken as the analysis path. The results show that, under the two different construction schemes, the pavement related structure changes with the direction and the vertical displacement value. As well as the longitudinal maximum tensile stress value of the size of the change. Analysis and comparison results are shown in Figure 4, Figure 5 and Figure 6.

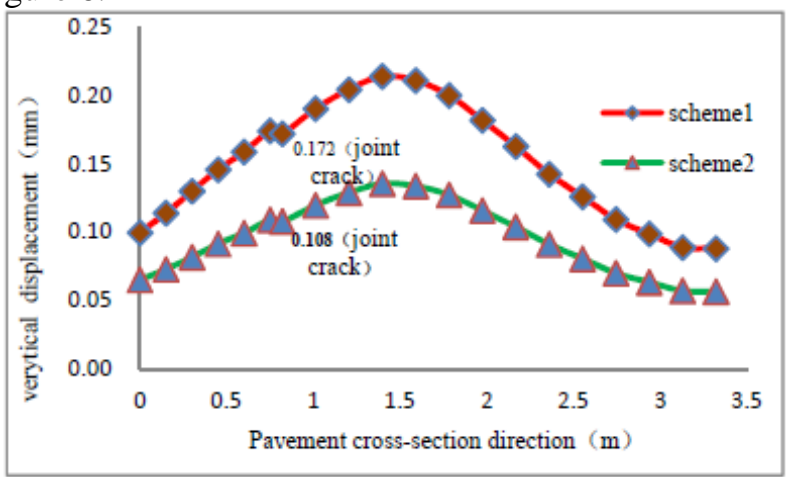

Figure 4.The maximum vertical displacement of new concrete base under the surface 


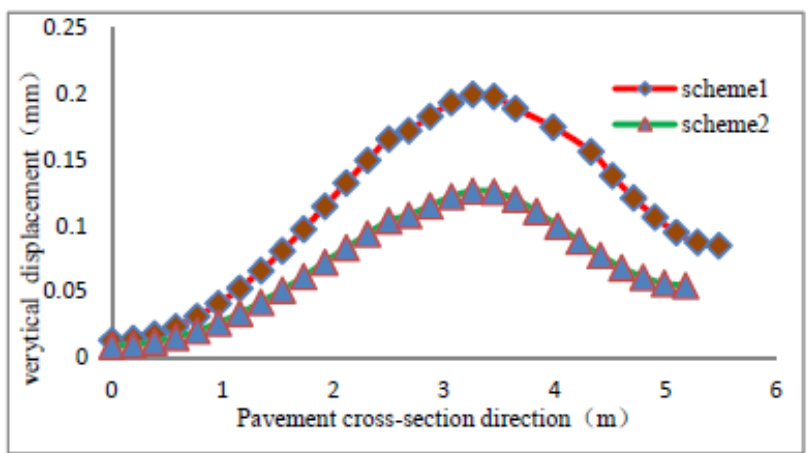

Figure 5. The maximum vertical displacement of the whole road layer under the surface

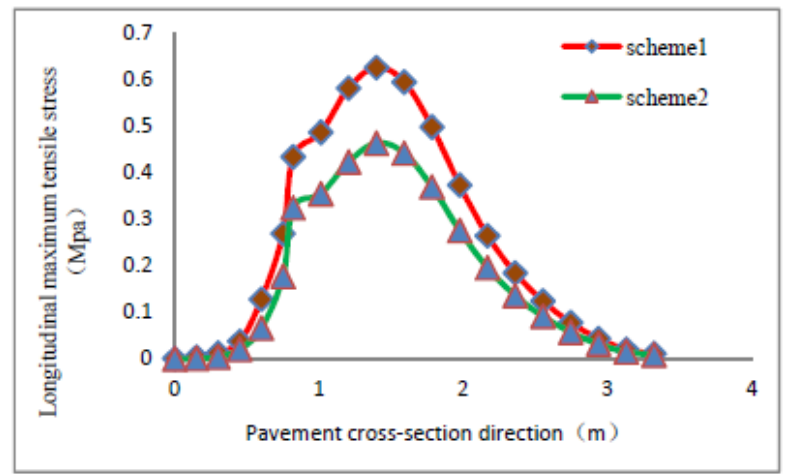

Figure 6. The maximum longitudinal tensile stress of new concrete base under the surface

From Figure 4, Figure 5, Figure 6, it can be drawn the following conclusions.

1) Construction scheme one: old and new pavement with plain concrete base splicing:

The results show that the maximum vertical displacement and longitudinal tensile stress of the pavement under the loading load are $0.319 \mathrm{~mm}$ and 533 knots respectively under the construction scheme. The calculated displacement is $0.172 \mathrm{~mm}$. In addition, the maximum vertical displacement of the lower surface of the new concrete basement is $0.219 \mathrm{~mm}$, and the maximum longitudinal tensile stress is $0.628 \mathrm{MPa}$.

2) Construction scheme two: old and new pavement joints when the upper part of the laying of steel reinforcement:

The results show that the maximum vertical displacement and longitudinal tensile stress of the pavement structure layer are just below the traffic load, the maximum vertical displacement of the pavement layer is $0.203 \mathrm{~mm}$, and the joint position is 533 nodes. The resulting displacement is $0.108 \mathrm{~mm}$. The maximum vertical displacement of the new concrete base is $0.138 \mathrm{~mm}$, and the maximum longitudinal tensile stress is $0.466 \mathrm{MPa}$. In addition, the vertical displacement distribution of the steel bars shows that the vertical displacement of steel bars in the position near the vehicle load is the largest; the maximum is $0.130 \mathrm{~mm}$, and the rest of the reinforcement displacement decreases with the distance from the vehicle load.

From the above two construction programs, the specific results of the comparison shown in Table 2 and Table 3.

The results of Table 2 and Table 3 show that the maximum vertical displacement of the lower surface of the whole pavement is $0.319 \mathrm{~mm}$ less than that of plain concrete under the same standard driving load. The maximum vertical displacement decreased by $36.36 \%$. The maximum vertical displacement of the lower concrete surface was reduced from $0.219 \mathrm{~mm}$ to $0.138 \mathrm{~mm}$, and the maximum vertical displacement decreased by $36.99 \%$. The vertical displacement The displacement from $0.172 \mathrm{~mm}$ to $0.108 \mathrm{~mm}$, the vertical displacement value decreased by $37.21 \%$; the maximum longitudinal tensile stress of the new concrete basement was reduced from $0.628 \mathrm{MPa}$ to $0.466 \mathrm{Mpa}$, The value of the maximum longitudinal tensile stress decreased by $25.80 \%$.

TABLE II. VAlues of Vertical DisPlacement under DifFERENT CONSTRUCTION SCHEMES

\begin{tabular}{ccc}
\hline $\begin{array}{c}\text { Construction } \\
\text { scheme }\end{array}$ & $\begin{array}{c}\text { The maximum vertical displacement of the lower } \\
\text { surface of the pavement }(\mathbf{m m})\end{array}$ & $\begin{array}{c}\text { Maximum Vertical Displacement of New Surface of } \\
\text { Concrete Base (mm) }\end{array}$ \\
\hline scheme 1 & 0.319 & 0.219 \\
scheme 2 & 0.203 & 0.138 \\
\hline
\end{tabular}

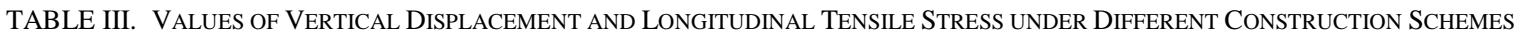

\begin{tabular}{ccc}
\hline $\begin{array}{c}\text { Construction } \\
\text { scheme }\end{array}$ & $\begin{array}{c}\text { Vertical displacement at the joint } \\
\text { displacement }(\mathbf{m m}) \\
(\mathbf{m m})\end{array}$ & $\begin{array}{c}\text { The Longitudinal Maximum Tensile Stress of New Surface of } \\
\text { Concrete Base (MPa) }\end{array}$ \\
\hline scheme 1 & 0.172 & 0.628 \\
scheme 2 & 0.108 & 0.466 \\
\hline
\end{tabular}




\section{CONCLUSION}

(1) The road has been put into use for nearly two years, the opening process of operation found that the quality of old and new pavement meet the normal use of the requirements, today there is no obvious longitudinal cracks and uneven differential settlement, the results show that the construction program Applicability and feasibility.

(2) This research program will be part of the new concrete paved directly on the old pavement, and then in the old and new pavement seam laying the upper part of the base directly with the new concrete pouring. Which is different from the traditional pavement structure of the excavation steps, but also avoid the need for the old pavement structure of the anchorage and other complex processes, it reflects the splicing technology is reasonable and superiority, and a certain degree of innovation, Can provide reference and reference for future similar projects.

(3) By comparing and analyzing the different pavement models, it is shown that the new reinforced concrete base in the upper part of the joints can reduce the stress concentration at the pavement joints, and to a certain extent reduce the structural layers of the pavement Deformation, so that the expansion of the longitudinal cracks can be reduced.

\section{REFERENCES}

[1] Ma Xiao-hui. Analysis of mechanical response of new-old splicing pavement structure of highway extension [D]. Shanghai: Tongji University, 2008: 37-38.

[2] Ma Xiao-hui, LI Li-han.Analysis of the step size of pavement in road widening $[\mathrm{J}]$. Journal of Highway and Transportation Research and Development, 2010 (5): 1-5.

[3] Xue Cheng. Study on Application of Pavement Construction Technology in Extension Project Pavement Construction [J]. 2009 (08): 55-60.

[4] Xiao Yi-min, LI Chang. Study on Pavement Structure Merging Technique of Extension Project of He-Ning Expressway [J]. Journal of Highway and Transportation Research and Development, 2009 (08).

[5] Xu Zhi-jie. New and old roadbed combined treatment technology and mechanism [D]. Master of Science, Changsha University of Science and Technology papers, 2005: 7-8.

[6] Liao Gong-yun, Huang Xiao-ming ABAQUS finite element software in the application of road engineering [M]. Nanjing: Southeast University Press, 2014: 274-286.

[7] Chang Lu, Lv De-bao, Sun Xiu-dong, et al. Discussion on influence of traffic lane design width on asphalt pavement disease and its measures [J]. Publication, 2002 (05): 91-94. 